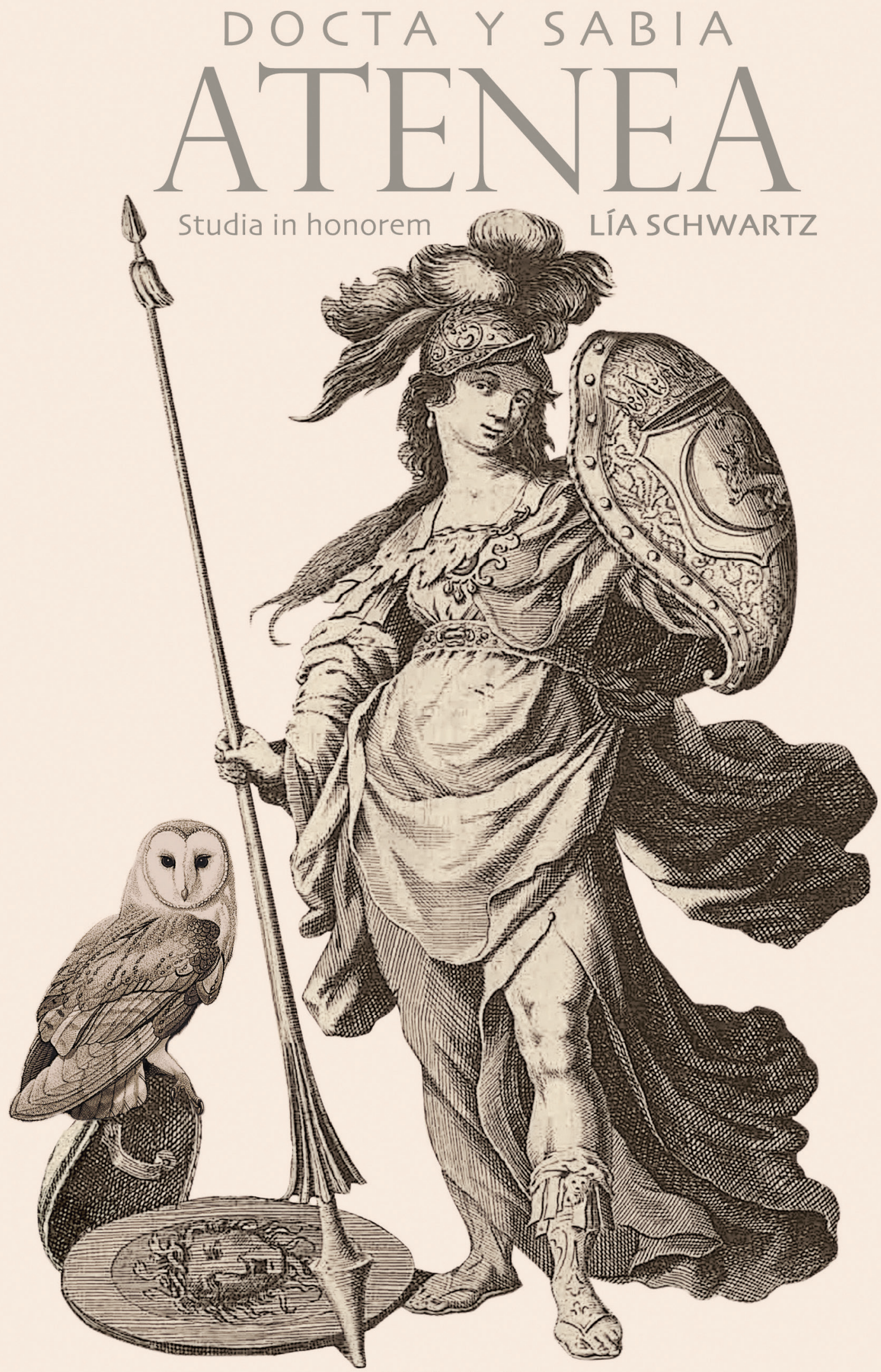

Edición al cuidado de:

SAGRARIO LÓPEZ POZA, NIEVES PENA SUEIRO, MARIANO DE LA CAMPA, ISABEL PÉREZ CUENCA, SUSAN BYRNE Y ALMUDENA VIDORRETA 



\section{DOCTA Y SABIA ATENEA Studia in honorem Lía Schwartz}

Edición al cuidado de:

Sagrario López Poza, Nieves Pena Sueiro, Mariano de la Campa, Isabel Pérez Cuenca, Susan Byrne y Almudena Vidorreta

A Coruña, 2019 

Profesora Lía Schwartz

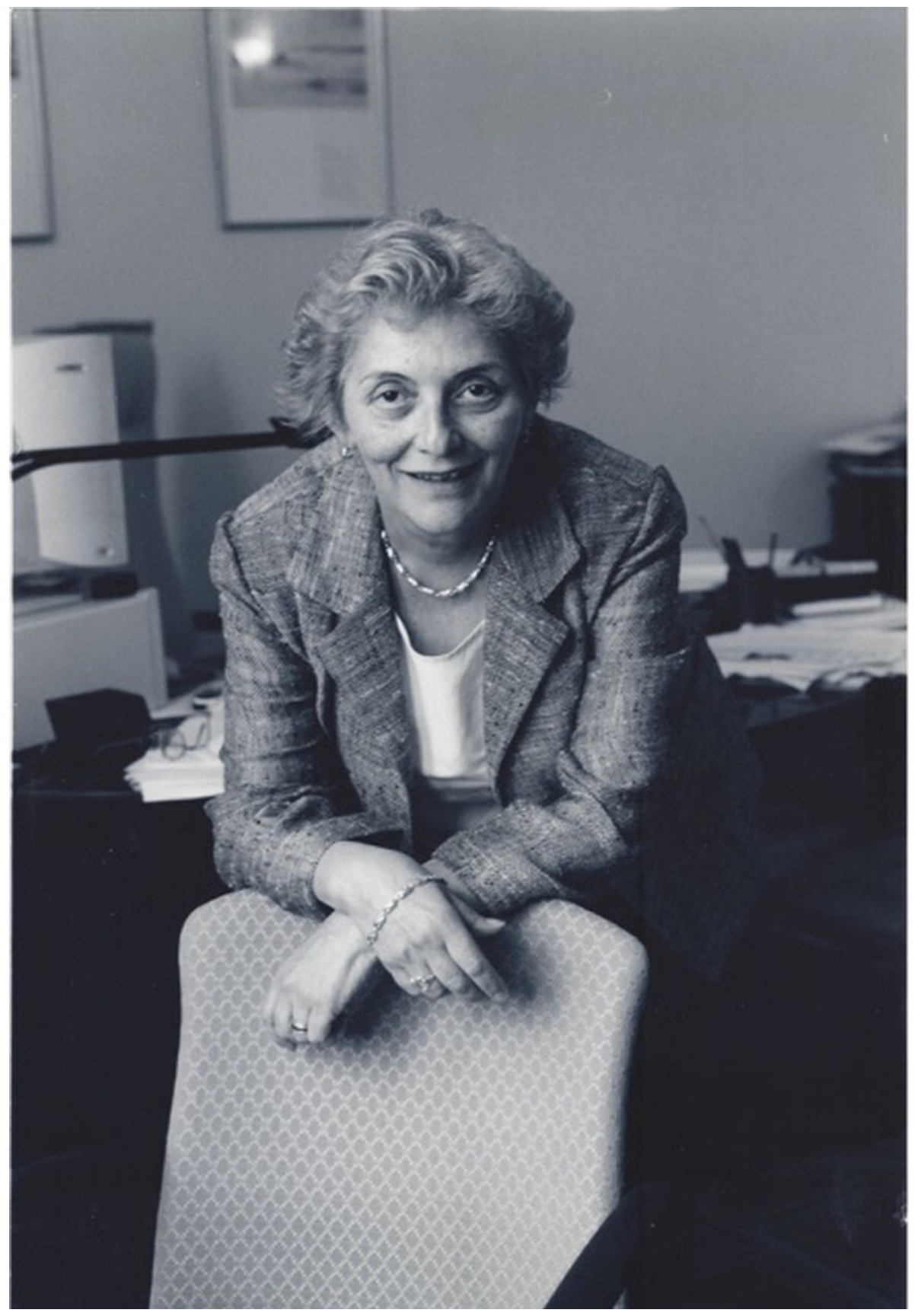


Sagrario López Poza, Nieves Pena Sueiro, Mariano de la Campa, Isabel Pérez Cuenca, Susan Byrne, Almudena Vidorreta (editores)

Docta y sabia Atenea. Studia in honorem Lia Schwartz

N. ${ }^{\circ}$ de páginas: 832

$17 \mathrm{x} 24 \mathrm{~cm}$.

Índice: pp. 7-10

ISBN: 9788497497046

Depósito Legal: C 53-2019

CDU: $821.134 .2(082.2) *$ SCHWARTZ

IBIC: DS | 2ADS | DQ

Editan:

Universidade da Coruña, Servizo de Publicacións

Instituto Universitario "La Corte en Europa" (IULCE), Universidad Autónoma de Madrid

Hispanic Seminary of Medieval Studies (HSMS), New York

Queen Sofía Spanish Institute, New York

Seminario Interdisciplinar para el estudio de la Literatura Áurea Española (SIELAE), Grupo Hispania, Universidade da Coruña

(C) Los autores

(C) De esta edición:

Servizo de Publicacións, Universidade da Coruña

Colección: Homenaxes n. ${ }^{\circ} 14$

Diseño de la cubierta: Paula Lupiáñez (Cirugía Gráfica. Madrid)

Interior: Juan de la Fuente

Impreso en Lugami Artes Gráficas, Betanzos (España)

Printed in Spain 


\section{ÍNDICE}

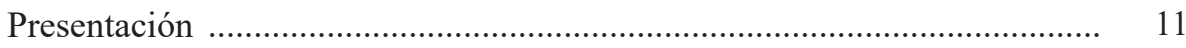

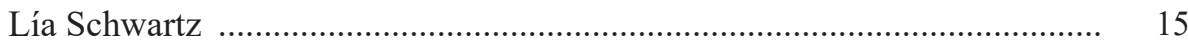

Bibliografía de Lía Schwartz ................................................................. 19

\section{Estudios en homenaje a la profesora Lía Schwartz}

Antonio Azaustre

Notas sobre la filiación en la tradición manuscrita de El alguacil endemoniado

Mercedes Blanco

Para una definición del gongorismo. El caso de Nueva España

69

JAVIER BLASCO

«Salta Pan, Venus baila, Bacho entona»: el campo léxico de la música como vehículo del erotismo en la poesía de los Siglos de Oro

SUSAN BYRNE

La armonía neoplatónica en "A Francisco de Salinas» de fray Luis de León

Mariano de La CAMPa

Poemas de Quevedo en impresos del siglo XVII: Los Romances varios .....

Manuel Ángel Candelas

La poesía española en los manuscritos de la Biblioteca Nazionale di Napoli: noticias y textos

ANTONIO CARREÑo

Lope de Vega: «Rompa ya el silencio el dolor en mí»

Donald CRUickshank

Don Toribio Cuadradillos, «avestruz del amor», and El lindo don Diego (with a note on Quevedo) 
María D'Agostino

Un juego de espejos deformantes. La «representación» del conde de Lemos entre Argensola y Cervantes

TREVOR J. DADSON

«Yo no puedo salir del trabajo de parecer a los portugueses castellano y a los castellanos portugués»: Diego de Silva y Mendoza y la poesía hispanoportuguesa de principios del siglo XVII

Ottavio Di Camillo

Of Roasted Eggs and Other Issues in the Celestina

Aurora EGIDO

Retórica y poética de los afectos en el soneto XIV de Garcilaso 265

Santiago Fernández Mosquera

El vicio de la virtud en Los trabajos de Persiles y Sigismunda 283

Flavia Gherardi \& Pedro Cátedra

El Discorso in difesa della poesia de Gian Ambrogio Biffi en el ámbito de la poética italiana y española

AdRIÁN M. IZqUiERDO

Paráfrasis y experimentación poética en el Anacreón castellano de Quevedo

HILAIRE KALLENDORF

Splitting Hairs or Finding Threads: The Labyrinth as Metaphor for Moral Dilemma in the Comedia

José ENRIQUE LAPLANA

La erudición en el Para todos de Juan Pérez de Montalbán

Begoña LóPEZ Bueno

El Ramillete de las Musas Castellanas (Bibliothèque Mazarine, ms. 4047): un canon literario español en el siglo XVII francés. Primera parte

SAGRARIo LóPez PozA

«Amoris vulnus idem sanat, qui fecit». Notas sobre la fortuna de un topos clásico

ISABEL LOZANO RENIEBLAS

El mal latín del episodio de dos falsos cautivos del Persiles 
Alison Maginn

Rubén Darío's Final Chapter: Archer Milton Huntington and the Hispanic Society

Miguel Martínez

Góngora asiático. Notas sobre poesía filipina inédita del primer Barroco ....

José Martínez MiLlán

Isabel Clara Eugenia, ¿una infanta castellana?

Clayton McCarl

Hacia un modelo para el marcado semántico de los textos marítimos de la época colonial

\section{Juan Montero Delgado}

Un soneto desconocido de Pedro Espinosa a Francisco de Rioja en el ms. Span 56 de la Houghton Library (Universidad de Harvard) 561

Nuria Morgado

Pervivencia del Barroco en la poética de la modernidad: intuiciones y conceptos en el pensamiento literario de Antonio Machado

FRANCISCA MOYA DEL BAÑo

La presencia de Plauto en Quevedo

VALENTINA NIDER

El oro como botín en los poemas de Quevedo sobre Belisario (B-267 e

B-281) y el contexto literario hispano-italiano

ISABEL PÉREZ CUENCA

Francisco de Quevedo y Antonio Sancho Dávila y Toledo Colonna, III marqués de Velada

FERnANDo Plata

El sentido de «barranco» en La Perinola de Quevedo y en otros textos del Siglo de Oro 653

José María Pozuelo Yvancos

Interdiscursividad: cine y literatura en Javier Cercas 671

Augustin Redondo

El tema de la mujer caída de una torre abajo: tradiciones culturales (grecolatinas, bíblicas, folklóricas), creencias religiosas y creaciones cervantinas ... 
MANUEl Rivero RODRÍGUEZ

El conde duque de Olivares, mecenas de la Historia y creador de opinión ... 701

MARIE RoIG Miranda

Los Sueños de Quevedo o cierto tipo de novela 723

Melchora Romanos

Séneca en las Anotaciones de Pedro Díaz de Rivas a los poemas mayores de Góngora

JAVIER SAN JosÉ LeRA

La Política de Dios de Quevedo como comentario bíblico: Política, Biblia y Literatura

LuIs SÁNCHEZ LAÍlLA

Ignacio de Luzán y la musa bucólica

Almudena Vidorreta

Teresa de Jesús, precursora de Gabriela Mistral y Alfonsina Storni

JUAN DiEgo VILA

«con las ansias de la muerte»: El aparato prologal del Persiles como programa estético del estilo tardío cervantino 


\title{
Un soneto desconocido de Pedro Espinosa a Francisco de Rioja en el ms. Span 56 de la Houghton Library (Universidad de Harvard)*
}

\author{
JUAN MONTERO \\ Universidad de Sevilla
}

Entre los tesoros bibliográficos que alberga la Houghton Library, el ms. Span 56 tiene especial interés para los estudiosos de la poesía española aurisecular. Rotulado como Poesías varias. 1631, el códice fue recopilado por el poeta, pintor y tratadista Francisco Pacheco del Río (1564-1644) y en sus 243 folios alberga 180 poemas de diferentes autores, con presencia muy destacada de los sevillanos o vinculados con los círculos poéticos de la ciudad ${ }^{1}$.

Aunque no se ha hecho hasta ahora el recuento exhaustivo de los testimonios únicos que aporta, este es uno de los aspectos destacados del Span 56. Como muestra, baste recordar que en él se contiene la única copia conocida del soneto de Cervantes a la muerte de Fernando de Herrera («El que subió por sendas nunca usadas»), con un encabezamiento bien llamativo, además:

* El presente trabajo se inscribe en el Proyecto I + D Del sujeto a la institución literaria en la Edad Moderna: procesos de mediación, (MINECO - FFI2014-54367-C2-2-R), dirigido por Juan Montero Delgado e Isabel Román Gutiérrez.

1 El códice se encuentra digitalizado aquí: <https://iiif.lib.harvard.edu/manifests/ view/drs:49602109\$1 >. Para los datos sobre la historia del manuscrito y su utilización por parte de los estudiosos, vid. Montero (2011: 343-353). En estas páginas seguiremos la numeración topográfica que dimos a los poemas en este trabajo. En las citas del ms., resolvemos las abreviaturas y regularizamos según la norma actual tanto la acentuación y la puntuación como el uso de mayúsculas y minúsculas. 
Miguel de Cervantes, autor de don Quixote, este soneto hize a la muerte de Fernando de Herrera, i para entender el primer cuarteto advierto que él celebraba en sus versos a una Señora debajo deste nombre de Luz. Creo que es de los buenos que e hecho en mi vida ${ }^{2}$.

Pues bien, en estas páginas vamos a centrarnos en lo que creemos que constituye otro caso de testimonio único (al menos hasta ahora) del Span 56; en este caso, un soneto del antequerano Pedro Espinosa (1578-1650) dirigido a Francisco de Rioja (1583-1659), poema desconocido hasta hoy por los editores y estudiosos de su obra ${ }^{3}$.

El soneto en cuestión está copiado en el f. 155v y lleva el n. ${ }^{\circ} 99$ en nuestro índice topográfico. Dice así:

Al museo del Señor Doctor Francisco de Rioja Licenciado Pedro de Espinosa

A aquella escuela de Minerva, aquella aula de Apolo, forastero, adora; prevén dignos aplausos desde aora para pagar cuando merescas vella.

Abre los ojos i los labios sella a la luz i al misterio que atesora; digo, a l'alma divina que la mora, lexos de la ciudad en medio d'ella.

Cuando de mil, no siete, celebradas maravillas te hallares impedido, atajado el discurso i el desseo, $i$ andes en cada passo mil jornadas, de informaciones arduas posseído, al dueño admirarás, i no al museo ${ }^{4}$.

2 Es el n. ${ }^{\circ} 118$, f. 169r. Se han ocupado del soneto, entre otros, Laskier Martin (1985), Lara Garrido (1999).

3 Sobre los avatares de la transmisión textual del antequerano, vid. Ruiz Pérez (2006) y (2011a: 22-45).

4 Hemos editado el texto siguiendo los criterios indicados en la n. 2. El texto original puede verse en la copia digital apuntada en la n.1 (p. 161 del archivo pdf). 
Digamos, de entrada, que el poema constituye el elogio a la vez de una morada («escuela de Minerva», «aula de Apolo», «museo») y de su habitante, a quien se atribuye un «alma divina». Todo visto desde la óptica de una voz poética admonitoria que pretende situar en la disposición adecuada el ánimo del «forastero» que se acerca a ese lugar y a quien lo ocupa. Ciertamente, la vivienda con su contenido («mil ... maravillas») ocupa el primer plano textual, mientras que las alusiones al morador se reservan para los versos que cierran los cuartetos $y$, finalmente, para el que concluye el poema. Esos versos encierran la clave de la composición: la admirable residencia recibe todo su valor de quien la habita, y no a la inversa ${ }^{5}$. En este sentido, el poema resulta ser la glosa, a manera de epigrama, de un conocido pasaje del De officiis ciceroniano en el que se proclama la superioridad de la virtud sobre los signos exteriores del rango social: «Ornanda enim est dignitas domo, non ex domo tota quaerenda, nec domo dominus, sed domino domus honestanda est $\rangle^{6}$. Que ese difundido manual estoico sea la fuente inmediata del poema constituye, sin duda, un dato que habrá que tener en cuenta a la hora de discutir su autoría. Como también, la apropiación y actualización de esa idea en los vv. 7-8, que introducen la noción de retiro o apartamiento.

5 Mutatis mutandis, es la idea que preside las Nenias que compuso Góngora en 1621, con ocasión de la muerte de Felipe III («Suspenda, y no sin lágrimas, tu paso, / oh peregrino errante»), que pondera las virtudes del difunto por encima del esplendor de su monumento funerario. Dice así la última estrofa: «Estas virtudes altamente santo / ejercitó el Tercero / de los Filipos. Tú, confuso en llanto, / las venera, y prosigue, oh forastero, / tus pasos antes que se acabe el día, / porque es breve aun del Sol la monarquía» (Canciones y otros poemas en arte mayor, 179).

6 Sobre los deberes, I, 139. Así lo tradujo Alonso de Cartagena en 1422: «Ca es de horrnar la dignjdad con casa, mas non es toda de buscar por la casa; njn el señor por la casa, mas la casa por el señor se deue honestar y honrrar» (Libro de los ofiçios, 77r). El pasaje ciceroniano tuvo difusión entre los autores españoles, como testimonian Juan de Arce de Otálora en los Coloquios de Palatino y Pinciano, II, 626; o Francisco López de Úbeda en La pícara Justina, II, 547. Una variante de la sentencia («Non domo dominus, sed domino domus») se empleó en la época como lema en el dintel de algunas casas señoriales (Razzal); todavía lo ostentaba la de Gioachino Rossini en Bolonia, construida allá por 1824-1827. El aserto del De oficiis tuvo escasa repercusión en la literatura aforística clásica y medieval. Tan solo se recoge una sentencia anónima en los fragmentos de obras dramáticas romanas, «Homo locum ornat, non hominem locus», y en un pasaje de una obra en verso de Beda el Venerable, «Nec loca propter homo merito venerabilis extat, / sed locus ob homines extat venerabilis almos» (Otto: 1890, n. ${ }^{\circ} 965$, p. 196). Agradezco a mi amigo y colega José Solís de los Santos estas últimas referencias. 
Como siempre que de atribuir un texto se trata, no faltan los problemas. Aquí empiezan por el mismo encabezamiento. Empezaremos por la identificación del dedicatario con el poeta sevillano que todos conocemos. En principio, esto no plantea mayores dificultades — aunque su tratamiento como Doctor requerirá de ulteriores consideraciones-, dado que, por un lado, Rioja y Pacheco tuvieron una relación bastante estrecha ${ }^{7}$, y que, por otro, el primero aparece nombrado en otros dos poemas del Span 56. En efecto, a él está dirigida la epístola moral de don Nufio de Colindres que empieza «A la temeridad de la fortuna» (n. ${ }^{\circ} 132$, ff. 188r-191r) ${ }^{8}$, y también se le menciona como uno de los asistentes a la boda de Juana Pacheco, la hija del pintor, con Velázquez, tanto en el encabezamiento como en el propio texto de un romance dedicado al tema ${ }^{9}$. Ninguna incertidumbre, por tanto, sobre quién es el Francisco de Rioja de nuestro soneto.

Por el contrario, en el caso del licenciado Pedro de Espinosa habrá que tomar alguna precaución adicional. Para ir despejando el terreno, empezaremos por recordar, ante todo, que el antequerano debió de ser, en efecto, licenciado, o por lo menos que así lo reconocieron sus contemporáneos ${ }^{10}$. Dicho esto, la presencia del determinativo «de Espinosa» no constituye en modo alguno un obstáculo insalvable para identificarlo, tentativamente

7 Véase al respecto la síntesis que ofrece Bassegoda i Hugas (1990: 27-28). Posteriormente, el mismo estudioso (2000-2001: 210-211) ha defendido que uno de los retratos pendientes de identificar en el Libro de retratos corresponde precisamente a Rioja. Es el retrato que tradicionalmente se ha dicho de Rodrigo Caro (Libro de retratos, 239).

8 Poco se sabe de este ingenio sevillano, mencionado por Juan Antonio de Ibarra en su Encomio de los ingenios sevillanos en la fiesta de los santos Inacio de Loyola $i$ Francisco Xavier, 83r. De otro poema de Colindres, en este caso un soneto a don Gaspar de Guzmán, todavía conde de Olivares, da noticia Barrera y Leirado (1867: 14).

9 El poema lleva este encabezamiento: «Romance que hizo el Licenciado Baltasar de Cepeda, aviéndose hallado en la boda de mi hija doña Juana Pacheco con Diego Velásquez, donde estuvieron el Dotor Sebastián de Acosta, el Padre maestro frai Pedro de Fromesta, i Francisco de Rioja, don Alonso de Ávila i otros muchos, en 13 de abril año de 1618» (n. ${ }^{\circ}$ 94, f. 146r). Y luego en el texto: «Rioja, fuente perenne, / dio ríos de sí, manando / mayor raudal que el que dio / al mundo el pie de Pegaso. / porque mostró un lugar solo / sobre el monte el del cavallo / i él descubrió más lugares / que piedras tiene el Parnaso» (f. 146v). El romance fue editado por Fichter (1960).

10 Por ejemplo, esta impresión napolitana: Espeio de cristal fino (...) compuesto por el Lic. Pedro Espinosa (1630). Pero no en las que él cuidó: «...el mismo título de licenciado que constantemente le atribuyeron sus contemporáneos al nombrarlo, bien que él, probablemente por modestia, jamás lo antepuso a su nombre, ni en las portadas de sus libros ni en ninguna de las firmas suyas que he examinado» (Rodríguez Marín, 2004: 57). 
al menos, con el colector de las Flores de poetas ilustres de España ${ }^{11}$. Y, de ser así, nada tendría de sorprendente que en algún momento hubiese dirigido un poema a Francisco de Rioja, habida cuenta de la vinculación que Espinosa tuvo con el círculo poético sevillano y, de manera más conocida, con Francisco Pacheco ${ }^{12}$. En cualquier caso, como a priori no puede descartarse que pudiera tratarse de un homónimo ${ }^{13}$, será preciso moverse en el terreno de la pura hipótesis hasta allegar otras pruebas. Y esto es lo que vamos a intentar ahora.

Empezaremos por las pruebas materiales y contextuales. El Span 56 es un códice que está conformado por una serie de cuadernillos, habitualmente de cuatro hojas, que suelen tener cierta unidad temática o autorial ${ }^{14}$. El soneto que nos ocupa está copiado, como se ha dicho, en el f. 155v, que es la última plana de un cuadernillo de cuatro hojas (ff. 152-155). El cuaderno solo tiene dos poemas, ambos copiados por la misma mano ${ }^{15}$, el soneto y una canción que ocupa las siete planas precedentes: «Canción de Don Josef de Saravia, secretario del Duque de Medina Sidonia con nombre impuesto de Trevijano» — dice el encabezamiento-, que empieza: «Ufano alegre, altivo, enamorado» ${ }^{16}$. La mención del empleo de Sarabia como secretario del Guzmán viene a favorecer la hipotética autoría de Espinosa para el

11 Pues se puede explicar como una mera y equivocada variación onomástica que se repite en documentos antiguos y que todavía hoy persigue a este autor. Un ejemplo antiguo nos lo dan Las Flores poéticas y justa (...) al triunfo de los desagravios del Santísimo Sacramento (1637), que incluye unas octavas que «...vinieron a nombre del Licenciado Pedro de Espinosa, Rector del Colegio de San Ildefonso de Sanlúcar» (Poesía, 301).

12 Es probable, como conjetura Rodríguez Marín, que tal vinculación datase de los tiempos en que Pedro Espinosa preparaba su edición de las Flores, en la que dio cabida a varios ingenios sevillanos, entre ellos el propio Pacheco. Como prueba de esa amistad nos ha quedado una carta del pintor al poeta con algunas consideraciones sobre la decisión de Espinosa de hacer vida eremítica, allá por 1606; la carta está editada en Rodríguez Marín (2004: 210-211). Una prueba adicional de la relación de Espinosa con los ambientes sevillanos la da su epístola a Antonio Moreno Vilches, cosmógrafo de la Casa de Contratación («Tú, que huellas el oro de las márgenes»).

13 Rodríguez Marín (2004: 58-59 y «Apéndice», vi) localizó, de hecho, varios homónimos del poeta.

14 Montero, en prensa.

15 Que en el citado trabajo en prensa proponemos identificar con la del amanuense que copió muchos de los códices de Pacheco, incluyendo el Libro de retratos.

16 Sobre este Saravia o Sarabia, vid. Blecua (1970); el erudito apunta un dato relevante, que Sarabia «...figura entre los amigos que elogian el Panegírico [al duque de Medina Sidonia, ¿Sevilla, 1629?] de Pedro Espinosa». Posteriormente, González Ollé 
soneto que nos ocupa, pues, como bien se sabe, el antequerano estuvo a su servicio durante décadas, desde c. 1615 hasta 1636, año en que falleció el duque. Por tanto, cabe pensar que la idea de quien confeccionó el cuadernillo era la de reunir en él sendos poemas de dos autores vinculados con el VIII duque de Medina Sidonia ${ }^{17}$. Si fue Pacheco el que tuvo esa idea o si se limitó a copiar o hacer copiar un modelo preexistente es algo difícil de determinar. En cualquier caso, el rótulo de la canción nos indica que la copia se hizo en una fecha indeterminada después del 3 de septiembre de 1628, que es cuando Sarabia entró al servicio del duque; y como muy tarde, podemos pensar en la fecha de 1631, que es la que ostenta el Span 56 en su portada ${ }^{18}$. Fechas que, en cualquier caso, se refieren por ahora a la copia, no a la composición del poema.

Pasemos ahora a los datos textuales, o sea, las similitudes de expresión, estilo e ideas entre el soneto y la obra conocida de Espinosa, tanto en prosa como en verso. Las que nos parecen las más relevantes son las siguientes:

\section{Abre los ojos i los labios sella (v. 5)}

La expresión sellar el labio o los labios para indicar un silencio lleno de respeto y asombro está documentada en este pasaje del Panegírico al Excmo. Sr. D. Manuel Alonso Pérez de Guzmán (1629): «Para repasar esta leción de Filosofía es tu soledad (menesteroso presidio del alma); en ésta, sellando el labio la paz, compones diferentes intentos debajo de un mismo silencio» ${ }^{19}$.

(1965: 8-10) ha podido documentar que Sarabia fue secretario de don Manuel Alonso Pérez de Guzmán desde el 3 de septiembre de 1628 hasta el 24 de abril de 1634.

17 Parece, en cambio, puramente accidental y anecdótico que el siguiente cuadernillo del ms. se inicie con un soneto (n. ${ }^{\circ} 100$, f. 156 r) de Barahona de Soto («Genil que ves la sombra en tu corriente»), pero que va rotulado como «De incierto autor».

$18 \mathrm{Y}$ también figura en un texto en prosa que precede a los tres últimos poemas de la colección. La única reserva sobre la fecha de 1631 nace del hecho de que algunos poemas pudieron copiarse después de estar formado el volumen, aprovechando las planas en blanco que habían quedado (y aún quedan) en algunos cuadernillos. Con todo, los rasgos de escritura del soneto, similares en todo a los de la canción de Sarabia que lo antecede, dan poca o ninguna verosimilitud a esta posibilidad.

19 Espinosa, 1991: 358. El paralelismo sintáctico en quiasmo del verso bimembre reaparece en otros versos de Espinosa, como «sacude el yugo, libertades canta» (Poesía, 189); o en un dístico: «rompa hielos del mar el anglio rubio / y España a Potosí las venas rompa» (Poesía, 222). 


\section{2. digo, a l'alma divina que la mora (v. 7)}

El uso de este digo para introducir una aclaración de lo dicho previamente no es raro en los versos de Espinosa. Tres ejemplos hemos encontrado en la relación que escribió del entierro del padre del duque al que sirvió ${ }^{20}$, dos de ellas como apertura de unidad métrica, al igual que en el soneto:

Por remate del túmulo, derecho pendía gravemente el estandarte, cuya punta tocó el dorado techo,

digo, la insignia real que, para el arte

de la milicia al General que ampara el océano todo entregó Marte.

Y ya casi al final del poema:

Dure eterna la gracia y bizarría del hermoso clavel y bellas flores que el nuevo abril en tiernos años cría,

digo los generosos sucesores de vuestra casa y sangre, de Medina y de Lerma gloriosos esplendores ${ }^{21}$.

\section{3. lexos de la ciudad en medio della (v. 8)}

Este magnífico endecasílabo, por la precisión y sencillez con que expresa una idea compleja, fue el que nos hizo sospechar que el soneto era realmente obra de un poeta de primera fila. Y ahora podemos ver que Espinosa emplea la misma expresión en el Panegírico, pero aplicada a la corte: «Con todo eso, en medio de la Corte, estuviste lejos de ella» ${ }^{22}$.

20 Relación de la forma en que se tuvo el entierro de don Alonso Pérez de Guzmán el Bueno, duque de Medina Sidonia (1615), que apareció sin nombre de autor.

21 Poesía, 178 y 370, respectivamente. Hay todavía un tercer ejemplo en el v. 81: «del muerto, digo, su señor primero» (Poesía, 174).

22 Espinosa, 1991: 336. El contexto aclara que la frase se refiere a que el Duque residió en la corte de Madrid sin compartir los vicios propios de ella: «Porque no heciste grandeza de la ignorancia, ni, cautelosamente afable, ganaste gracia con la falsedad, ni obligaste con agravio...». También, entre la retahíla de los espantos del mundo que el Perro 


\section{Cuando de mil, no siete, celebradas (v. 9)}

La misma ponderación numérica se da en este verso de Espinosa: «Con mil, no siete brazos, como el Nilo» ${ }^{23}$.

\section{5. atajado el discurso i el deseo, (v. 11)}

La construcción atajar el discurso se documenta un par de veces en Espinosa, una en el Panegírico: («No con bárbaro Marte ni atajado discurso...»), y otra en una silva en alabanza del mismo duque: «La calumnia, que corta más que espada, / atajado el discurso, afirma o duda $»^{24}$.

\section{6. al dueño admirarás, i no al museo (v. 14)}

Otro endecasílabo notable. La misma idea y en términos muy similares la despliega Espinosa en la Soledad del Gran Duque, cuando amonesta: «admiren más al dueño que a tu casa» ${ }^{25}$.

A estas semejanzas se podrían añadir otras de menor entidad, cifradas en ciertas palabras del soneto que el CORDE reconoce como propias de la lengua poética de Espinosa. Es el caso de escuela(s), forastero (sustantivo), prevenir, digno como calificación de un término del campo semántico del

escucha de boca de la Calentura en la obra epónima, figura este: «[No te espantes:] De ermitaño de corte» (Obra en prosa, 168), idea que recuerda un pasaje de la Regula Monachorum que Lupus de Oliveto (¿1370?-1433) pergeñó a partir de diferentes escritos de San Jerónimo y que Erasmo recogió en su edición de las epístolas del Estridonense: «et ut apertius loquar, plus te quod dicis habere mercedem, si in media urbe consistens monachus uictites» («Y para hablar con más desahogo, afirmas que tienes más ganancia si estableciéndote en medio de la ciudad, vivieras como un monje»; citamos por Opus epistolarum, 276). Sobre la cuestión del retiro en Espinosa y en el entorno ducal de Medina Sidonia, vid. ahora Escobar Borrego (2016). Por otra parte, la voz ciudad se documenta hasta diez veces en los versos de Espinosa, según el CORDE.

23 Poesía, 264. El uso ponderativo de mil se repite en el v. 12 («i andes en cada passo mil jornadas») y en otros versos de Espinosa. Un par de ejemplo con pasos: «Saldrate a recebir en azahares / mil pasos el jardín...» y «Mil pasos entre calles de azahares» (Poesía, 198 y 224). A propósito del citado v. 12, puede recordarse, a modo de contrapunto, este pasaje del Perro y la calentura: «...macho de noria, que camina mucho y no hace jornada» (Obra en prosa, 214).

24 La primera cita en Espinosa, 1991: 355; la segunda en Espinosa, 2011: 280.

25 Espinosa, 2011: 190. 
elogio ${ }^{26}$, aplauso, pagar, morar, ciudad, maravillas, información, poseer en sentido pasivo para indicar un estado de ánimo ${ }^{27} \mathrm{o} d u e \tilde{n} o^{28}$.

En definitiva, creemos que las similitudes de léxico y expresión que hemos podido detectar tienen la contundencia suficiente como para avalar la autoría de Espinosa. Lo mismo cabe decir de la idea central del poema: la celebración de alguien capaz de vivir retirado en medio de la ciudad y cuya grandeza no se cifra en lo que posee sino en la propia virtud del ánimo, rasgos que podemos asociar, como ya se ha dicho, con el pensamiento estoico que profesó Espinosa y que reconoció o proyectó en su visión literaria del VIII duque de Medina Sidonia ${ }^{29}$. En consecuencia, trataremos ahora de insertar ese poema en su trayectoria vital y creadora.

Para ello habrá que empezar por proponer una posible fecha para el soneto. Por el lado de Espinosa, hay que descartar, de entrada, los años de preparación de las Flores, por la excesiva juventud de Rioja por entonces, como seguramente también hay que descartar la etapa eremítica de Pedro de Jesús (1606-1614). Esto nos lleva a tomar el año de 1615 como término a quo para la composición del soneto y el de 1631, por las razones antes indicadas, como término ante quem. Nos movemos, por tanto, en un periodo de tiempo en el que Espinosa estuvo al servicio del Duque.

Para avanzar por el otro lado, hay que plantearse, en primer lugar, esta cuestión: ¿qué museo de Rioja es este que Espinosa celebra en sus versos? ¿Y en qué ciudad, Sevilla o Madrid, deberíamos ubicarlo? Por lo que se lee en los tercetos, parece necesario entender que el poema se refiere a un gabinete de curiosidades (maravillas) en el que Rioja habría ido reuniendo objetos de diferente naturaleza y que podían tener un interés científico, arqueológico o artístico, si bien, dada la personalidad del propietario,

26 Así encontramos dignos loores (Espinosa, 2011:177) o dignísimos loores (Espinosa, 2011: 181).

27 Como en este pasaje del Panegírico: «se dejó poseer de impaciente dolor» (Espinosa, 1991: 336).

28 Por el contrario, también hay en el soneto algunas palabras que no se documentan en los versos de Espinosa: aula, misterio, atesorar, arduo y museo. Pero esto no constituye en sí mismo prueba en contra de la autoría.

29 Recuérdese, entre otros posibles, al menos este pasaje del Panegírico al Duque (1629): «Allí te leemos el conmonitorio de Focílides, la doctrina de Epicteto y Séneca, las cartas de San Pablo, los libros de Job, los Sapienciales de Salomón...» (Espinosa, 1991: 361). Vid. al respecto las observaciones de López Estrada (Espinosa, 1991: 88-90); y Begoña López Bueno (2015: 27). 
habría que dar la preeminencia en este caso a las antigüedades y piezas de $\operatorname{arte}^{30}$. De ahí que el nombre de museo cuadre bien con lo que parece una colección de objetos cuantificados en abundancia (mil) y expuestos a la vista, pues basta dar un paso para recibir por los ojos informaciones arduas y dignas de admiración — sin que esto excluya para nada la presencia de libros - ${ }^{31}$. A nuestro juicio, la ubicación más verosímil de ese museo es la ciudad de Sevilla ${ }^{32}$, aunque solo sea porque no hay en el soneto la menor alusión a la corte o a la condición de cortesano que tuvo Rioja en diversos momentos de su vida: 1621-1627; 1630-c. 1643; 1654-1659; periodos a los que habría que añadir una estancia previa, todavía mal conocida, en la corte, acaso entre principios de 1615 y abril de $1618^{33}$. Está claro que de esos cuatro trechos solo podemos tomar en cuenta los dos más tempranos. Pero si Espinosa visitó la Corte por esas fechas, tal visita no ha quedado documentada, y desde luego es más que improbable, pues por entonces estaba cerca del Duque, expresamente retirado en sus dominios sureños. Por lo tanto, lo más verosímil es que el soneto fuese compuesto con ocasión de alguna estancia de Espinosa en Sevilla, donde el Duque mantenía su palacio y otras casas, sea entre 1615 (con las reservas antes indicadas) y 1621, sea entre 1627 y 1630 . Aunque la convivencia en el códice del soneto con la canción de Sarabia - quien, como se ha dicho, fue secretario del Duque entre septiembre de 1628 y abril de 1634-, otorga mayor grado de probabilidad al segundo de esos tramos, no se puede descartar que dicha

30 El caso es que, hasta hoy, no tenemos prácticamente noticias concretas sobre las aficiones de Rioja como coleccionista. En un pasaje del Arte de la pintura, 519, dice Pacheco que Rioja es propietario de un bodegón que él pintó en 1625.

31 Apunto, al respecto, una de las de las acepciones que recoge el Diccionario de Autoridades para museo: «Se toma también por el lugar en que se guardan varias curiosidades pertenecientes a las ciencias, como algunos artificios mathemáticos, pinturas extraordinarias, medallas antiguas, etc.». Para las concomitancias entre los conceptos de museo y de biblioteca, véase la revisión del tema que ofrece Ruiz Pérez (2011b).

32 Denominación que Espinosa emplea, por ejemplo, en este pasaje del Bosque de doña Ana (1624): «...y los señores se entretuvieron en oír una comedia que representó la compañía de Tomás Fernández y Amarilis, a quien el Duque tuvo por su cuenta en la ciudad de Sevilla desde el Miércoles de Ceniza» (Espinosa, 1991: 388-389).

33 Véase al respecto Mercedes Cobos (1987); es interesante subrayar que en una de esas cartas, fechada a 19 de diciembre de 1615, se menciona el «estudio» de Rioja en Madrid, lo que parece indicar un asentamiento estable del poeta. También Lope de Vega, en El jardín de Lope de Vega, epístola VIII de La Filomena (1621), dirigida «al licenciado Francisco de Rioja, en Sevilla», parece aludir a una estancia suya en la corte, luego interrumpida: «tú, que del cortesano mar las olas / cuerdo olvidaste...» (Vega, 1983: 819). 
combinación material responda al momento de la copia y no necesariamente al de la composición del soneto.

Todavía en relación con la fecha del poema, conviene subrayar un aspecto llamativo del mismo: la postura de admiración que expresa Espinosa por alguien que era cinco años más joven que él y que, como mucho, no tendría otro título académico que el de licenciado (o sea, el mismo que se le atribuye a Espinosa) cuando fue objeto de su homenaje poético $^{34}$. Como también llama la atención que este homenaje incida justamente en esa condición de docto, más que en la de poeta, por parte de Rioja. Sin embargo, tampoco esto es criterio definitivo para decantarse por uno de los trechos cronológicos antes mencionados, pues contamos con diversos testimonios que reconocen en Rioja un sujeto de erudición poco común, perito en las lenguas clásicas, y eso ya en una fecha relativamente temprana como la de 1609, a sus 26 años: «Rioja, proprio en el idioma extraño, / dilate la romana y griega historia», en palabras de Lope ${ }^{35}$. Lo que sí queda descartado - dicho sea de paso - es que haya que tomar al pie de la letra el tratamiento de doctor que le otorga a Rioja el encabezamiento del poema, ya que, como señaló Jean Coste, dicho tratamiento no lo recibe el sevillano hasta una fecha bastante tardía de su vida ${ }^{36}$. Por tanto, se trataría más bien de una fórmula de respeto dirigida a una persona que desde muy joven gozaba de reputación y prestigio social, si es que no estamos ante una simple errata del copista al transcribir un Don en abreviatura y con la $n$ volada.

34 Como señala Begoña López Bueno (1984: 16-17), las menciones de Rioja como licenciado menudean a partir de 1610 , pero no se conoce hasta hoy documento que acredite dicho grado.

35 Jerusalén conquistada, XIX, octava 83. Por las mismas fechas, lo califica Quevedo como «hombre en España de singular juicio y buenas letras» en el Anacreón castellano (Quevedo, 1971, IV: 274-275).

36 Coste (1965: 143) sitúa la graduación como doctor de Rioja «por junio de 1647, cuando andaba ya en los sesenta y cuatro años». Pero no lo afirma por haber localizado el acta de colación, sino simplemente porque en una documentación que edita correspondiente a ese año el poeta recibe el tratamiento de licenciado hasta el 29 de mayo de 1647 y el de doctor después del 23 de julio. Desde nuestro punto de vista, no hay seguridad de que Rioja llegase realmente a alcanzar nunca el grado de doctor, de manera que las oscilaciones en el tratamiento que refleja la documentación podrían ser simples descuidos. De hecho, el propio Coste (1969: 12) ha rescatado al menos otro documento, este fechado el 26 de abril de 1646, donde ya se le da a Rioja, al menos una vez, el tratamiento de doctor. 
En cuanto a la ubicación concreta del museo, hemos de conformarnos con algunas hipótesis a partir de los datos recogidos por Jean Coste en su trabajo recién citado sobre las casas de Rioja en Sevilla. La documentación manejada por el estudioso francés identifica hasta tres de esas viviendas, de las cuales una no llegó a habitarla en persona. Nos quedamos, por tanto, con dos: una que estaba en las inmediaciones del monasterio cisterciense de San Clemente el Real, situado en el extremo suroeste de la ciudad, y otra en la antigua calle de Moros, que podría identificarse, sea con la que actualmente se llama Heliotropo, muy cerca de la iglesia de San Marcos, en la zona norte del casco antiguo, sea con una calleja aledaña a la parroquia de San Román, en la misma zona norte, o todavía con una calle sin identificar en la parroquia de Santa Cruz, cerca de la Catedral ${ }^{37}$. Si los vv. 7-8 del soneto han de tomarse en un sentido material y no puramente mental o anímico, es obvio que cuadran mejor con la ubicación de la segunda de esas casas, de la que sabemos, además, que guardaba «una librería de mucha estima» ${ }^{38}$. Lamentablemente, no es posible precisar desde cuándo fue Rioja propietario de ninguna de esas dos viviendas sevillanas y si estas fueron o no las únicas que habitó en su edad adulta.

Es inevitable, por último, preguntarse al menos por qué un soneto como este, de indudable interés poético y dirigido a uno de los ingenios que descollaban en el panorama literario de la época, ha quedado al margen de la transmisión de los poemas de Espinosa. Ciertamente es llamativo, y más todavía si tenemos en cuenta que en buena medida dicha transmisión tuvo un cauce sevillano, como testimonia el famoso códice, hoy perdido, de la Biblioteca del Palacio Arzobispal de Sevilla ${ }^{39}$. Si es cierta la hipótesis

37 Collantes de Terán et al. (1993: II, 114). De la existencia de la casa vecina a San Clemente ya había dado noticias López Sedano (1774: xxix). La fuente está en los adicionadores de Rodrigo Caro: Rioja «...labró o amplió una casa retirada del comercio, cerca del monasterio de San Clemente para poderse emplear con más quietud en sus estudios, adornándola de muchas fuentes y jardines, y otras preciosas alhajas, siendo las principales sus libros»; apud López Bueno (1984: 32).

38 Así se dice en un poder otorgado en Madrid, el 09-08-1659, por don Alonso Fajardo de Roda, caballero de Calatrava, albacea y heredero de Francisco de Rioja, a favor del doctor don Diego de Castillo, canónigo de la Santa Iglesia de Sevilla (Coste, 1969: 20).

39 Es el códice conocido como «de Barahona» o «de Pamones», que había pertenecido al Conde del Águila. Está descrito parcialmente en Rodríguez Marín (2004: 358-359). Véase ahora la reconstrucción de la parte final del códice, donde se copian los poemas de Espinosa, que ofrece Ruiz Pérez (2011a: 36-39). 
de que ese códice autorial tuvo su origen en los cartapacios que Espinosa remitió a Rodrigo Caro allá por 1623, esto sería un indicio adicional a favor de fechar la composición del soneto entre 1627 y 1630, coincidiendo con uno de los paréntesis en la vida cortesana de Rioja. Dicha fecha explicaría que, aun circulando por Sevilla, el poema no fuese incorporado a la colección de versos de Espinosa recopilada en el presunto cartapacio de Caro.

Finalmente, hay otro indicio poderoso a favor de la datación del soneto entre 1627 y 1630: la publicación, seguramente en Sevilla y en 1629, del Panegírico al Duque. El libro lleva, en efecto, una aprobación del Doctor Esteban de Villa Real «en Sevilla a 27 de abril de 1629 años» y con la misma fecha una licencia firmada, también en Sevilla, por Luis Venegas de Figueroa, «gobernador, provisor y vicario general de Sevilla y su arzobispado», además de la ya citada carta del secretario Sarabia al autor, fechada en Sanlúcar a 17 de febrero de $1629^{40}$. No es descabellado suponer, entonces, que el propio Espinosa — ijunto con Sarabia? — pudo desplazarse a Sevilla para ocuparse personalmente de la impresión del opúsculo y que fue en esta ocasión cuando compuso el soneto, que lógicamente habría acabado en manos de sus amigos sevillanos, Pacheco entre ellos. La madurez estilística y conceptual del mismo no desdice de esa datación, ciertamente. E incluso son varios los lugares paralelos que presenta el poema con el texto del Panegírico; en concreto, los que en nuestra relación llevan los núms. 1,3 y $5^{41}$. De estos, el que mayor relieve tiene es el segundo, pues conecta el endecasílabo «lexos de la ciudad en medio d'ella» con esta sentencia referida al Duque: «Con todo eso, en medio de la Corte, estuviste lejos de ella». Situado en el eje estructural del soneto, ese verso se convierte en lema de la aristocracia espiritual que Espinosa reconoce en Rioja, y el eco del subtexto prosístico no hace sino potenciar su carácter encomiástico, al parangonar implícitamente a los dos homenajeados. O sea, que la analogía viene a subrayar la dignidad de un grupo social, el de los letrados, si no frente, sí al menos junto a la de los nobles de sangre. Y de paso, también queda realzada la dignidad de la voz poética que da cauce a este discurso, por su inequívoca adscripción a ese grupo de los letrados.

40 Espinosa, 1991: 328 y 330. El libro, que carece de notas tipográficas, es muy raro; Rodríguez Marín (2004: 342-343) maneja un ejemplar que fue de Sancho Rayón y antes seguramente de Gallardo.

41 Al tiempo que las numeradas como 4 y 6 remiten a composiciones incluidas en el Elogio al retrato del Duque, impreso en 1625; es decir, en fecha no lejana de 1629. 
Esta datación, en fin, también ayuda a entender que no conozcamos una hipotética respuesta de Rioja al soneto. Todo indica que, para esas fechas, el cronista y bibliotecario había renunciado al cultivo del verso.

Si nuestra hipótesis es cierta, el soneto cobra particular interés dentro de la producción de Espinosa, al tratarse de uno de los pocos textos poéticos suyos posteriores a 1625 que conocemos, y el único de carácter no devoto $^{42}$.

\section{BIBLIOGRAFÍA}

Arce de Otálora, Juan de, Coloquios de Palatino y Pinciano, ed. José L. Ocasar Ariza, Madrid, Turner, 1995.

Barrera y Leirado, Cayetano Alberto de la, Poesías de Francisco de Rioja, Madrid, Sociedad de Bibliófilos Españoles, 1867.

Bassegoda i Hugas, Buenaventura, «Introducción», en Francisco Pacheco, Arte de la pintura, Madrid, Cátedra, 1990.

Bassegoda i Hugas, Buenaventura, «El Libro de retratos y la verdadera efigie de don Diego Hurtado de Mendoza», Locus amoenus, 5, (2000-2001), pp. 205-216.

Blecua, José Manuel, «El autor de la canción "Ufano, alegre, altivo, enamorado"» [1957], en Sobre poesía de la Edad de Oro, Madrid, Gredos, 1970, pp. 255-256.

Cartagena, Alonso de, trad. Marco Tulio Cicerón, Libro de los ofiçios, transcripción de María Morrás, ed. de José Luis Villacañas Berlanga, Biblioteca Saavedra Fajardo de Pensamiento Político Hispánico. <http://www.saavedrafajardo.org/ Archivos/LIBROS/Libro0165.pdf> [consultado el 21.01.2018].

Cobos, Mercedes, «Dos cartas en torno a la polémica concepcionista. Algunos nuevos datos sobre Francisco de Rioja y Juan de Espinosa», Archivo Hispalense, 214 (1987), pp. 115-122.

Coste, Jean, «Francisco de Rioja, albacea del tesorero Juan de Asiaín Ugalde», Archivo Hispalense, 132-133 (1965), pp. 139-143.

Coste, Jean, Las casas sevillanas de Francisco de Rioja, Madrid, 1969.

Collantes de Terán, Antonio [et al.], (dir.), Diccionario histórico de las calles de Sevilla, Sevilla, Consejería de Obras Públicas y Transportes - Ayuntamiento de Sevilla, 1993.

42 Condición que sí tienen, en cambio, los rescatados por Molina Huete (2009) de una justa antequerana impresa en 1637. 
Escobar Borrego, Francisco Javier, «¿Topografía o topotesia en el entorno espiritual del Conde de Niebla?: sobre Soledades contemplativas y el Retrato de Pedro Espinosa (con dos documentos inéditos)», e-Spania [En ligne], 23 | février 2016, mis en ligne le 01 février 2016, consulté le 31 janvier 2018. URL: <http://journals. openedition.org/e-spania/25264>; <https://doi.org/10.4000/e-spania.25264>.

[Espinosa, Pedro], Relación de la forma en que se tuvo el entierro de don Alonso Pérez de Guzmán el Bueno, duque de Medina Sidonia, [Sevilla Alonso Rodríguez Gamarra], 1615.

Espinosa, Pedro, Espeio de cristal fino, Nápoles, Iuan Domingo Roncallolo, 1630.

Espinosa, Pedro, Obra en prosa, ed. Francisco López Estrada, Málaga, Diputación Provincial, 1991.

Espinosa, Pedro, Poesía, ed. Pedro Ruiz Pérez, Madrid, Edhasa (Castalia), 2011.

Fichter, William L., «Una poesía contemporánea inédita sobre las bodas de Velázquez», en Varia Velazqueña, Madrid, Dirección General de Bellas Artes, 1960, I, pp. 636-639.

Las Flores poéticas y justa (...) al triunfo de los desagravios del Santísimo Sacramento, Antequera, Juan Bautista Moreira, 1637.

Góngora, Luis de, Canciones y otros poemas en arte mayor, ed. José Ma . Micó, Madrid, Espasa-Calpe, 1990.

González Ollé, Fernando, «Biografía de José de Sarabia, presunto autor de la Canción real a una mudanza», Revista de Filología Española, 46 (1965), pp. 1-30.

Ibarra, Juan Antonio de, Encomio de los ingenios sevillanos en la fiesta de los santos Inacio de Loyola i Francisco Xavier, Sevilla, Francisco de Lyra, 1623; ed. Antonio Pérez y Gómez, Valencia, Tipografía moderna, 1950.

Jerónimo, San, Opus epistolarum Hieronymi Stridonensis (...) cum scholiis Des. Erasmi Roterodami, Apud inclytam Basileam, ex officina Frobeniana, 1537.

Lara Garrido, José, «Sonetos epicédicos en homenaje del divino Herrera. El rastro tenue de una fama póstuma», en Relieves poéticos del Siglo de Oro. De los textos al contexto, Málaga, Universidad de Málaga, 1999, pp. 111-148.

Laskier Martin, Adrianne, «El soneto a la muerte de Fernando de Herrera: texto y contexto», Anales Cervantinos, 23 (1985), pp. 213-222.

López Bueno, Begoña, «Introducción», en Francisco de Rioja, Poesía, Madrid, Cátedra, 1984

López Bueno, Begoña, «La Soledad del Gran Duque de Medina Sidonia. El vasallaje poético de Pedro Espinosa», en José M. Rico García y Pedro Ruiz Pérez (eds.), El duque de Medina Sidonia. Mecenazgo y renovación estética, Huelva, Servicio de Publicaciones de la Universidad de Huelva, 2015, pp. 21-44.

López Sedano, Juan J., Parnaso Español, vol. VII, Madrid, Antonio de Sancha, 1774.

López de Úbeda, Francisco, La pícara Justina, ed. Antonio Rey Hazas, Madrid, Editorial Nacional, 1977. 
Molina Huete, Belén, «Nuevas flores poéticas de Pedro Espinosa y Cristobalina Fernández de Alarcón: un reencuentro con olvidados poemas de certamen», Analecta Malacitana, 26 (2009), pp. 123-145.

Montero, Juan, «El ms. Span 56 de la Houghton Library (Universidad de Harvard): índice topográfico», en Antonio Azaustre Galiana y Santiago Fernández Mosquera (eds.), Compostella aurea. Actas del VIII Congreso de la AISO, vol. I, Santiago de Compostela, USC-Publicacións, 2011, pp. 343-353.

Montero, Juan, «El taller poético del pintor Pacheco: el ms. Span 56 de la Houghton Library (Universidad de Harvard)», en prensa.

Otto, August, Die Sprichwörter und sprichwörtlichen Redensarten der Römer, Leipzig, Teubner, 1890.

Pacheco, Francisco, Arte de la pintura, ed. Buenaventura Bassegoda i Hugas, Madrid, Cátedra, 1990.

Pacheco, Francisco, Libro de retratos, ed. de Pedro M. Piñero Ramírez y Rogelio Reyes Cano, Sevilla, Diputación Provincial, 2001.

Poesias varias. 1631, [recop. Francisco Pacheco], ms. Span 56 de la Houghton Library (Universidad de Harvard) < https://iiif.lib.harvard.edu/manifests/view/ drs:49602109\$1i.>.

Quevedo, Francisco de, Obra poética, ed. José Manuel Blecua, Madrid, Castalia, 1971.

Razzal, Lucy, «Non Domo Dominus, sed Domino Domus», Centre for Material Texts, <https:/www.english.cam.ac.uk/cmt/?p=775> [consultado el 21.01.2018].

Rioja, Francisco de, Poesía, ed. Begoña López Bueno, Madrid, Cátedra, 1984.

Rodríguez Marín, Francisco, Pedro Espinosa. Estudio biográfico, bibliográfico y crítico [1907], ed. Belén Molina Huete, Málaga, Universidad de Málaga, 2004.

Ruiz Pérez, Pedro, «Pedro Espinosa: cuestiones de transmisión, fortuna crítica y poética histórica», Studia aurea, 1, (2006) <http://studiaaurea.com/article/view/ v1-ruiz/1>.

Ruiz Pérez, Pedro, «Introducción», en Pedro Espinosa, Poesía, ed. Madrid, Edhasa (Castalia), 2011a.

Ruiz Pérez, Pedro, «El museo del discreto: Para un ideario de la biblioteca en a España áurea (y una revisión del modelo graciano)», Rivista di Filologia e Letteratura Ispaniche, 14 (2011b), pp. 31-56.

Vega, Lope de, Jerusalén conquistada, ed. Joaquín de Entrambasaguas, Madrid, C.S.I.C., 1951.

Vega, Lope de, Obras poéticas, ed. José M. Blecua, Barcelona, Planeta, 1983. 